\title{
Exploring the screening capacity of the European Portuguese version of the 15-item Geriatric Depression Scale
}

\author{
João L. Alves Apóstoloㄹ, Elzbieta M. Bobrowicz-Campos ${ }^{1}$, Ivo A. Carvalho dos Reis ${ }^{2}$, Susana Justo \\ Henriques $^{3}$ and Carla A. Veiga Correia ${ }^{4}$ \\ ${ }^{1}$ Health Sciences Research Unit: Nursing, Nursing School of Coimbra, Coimbra, Portugal. \\ ${ }^{2}$ ARS Centro, Alfarelos, Portugal. \\ ${ }^{3}$ Associação de Solidariedade Social de Ribeira de Fráguas, Albergaria Velha, Portugal \\ ${ }^{4}$ ARS Centro, Coimbra, Portugal
}

\begin{abstract}
The aim of this study was to analyze the screening performance of the European Portuguese version of the 15 -item Geriatric Depression Scale (GDS-15) against DSM-5 diagnostic criteria for major depressive episode. The study was multicentre and involved 139 older adults recruited in the context of primary healthcare. Twenty-three participants were diagnosed with clinical depression. Sensitivity and specificity for different cut-off points were determined based on ROC curve analyses. The cut-off point $\geq 4.5$ provided optimal sensitivity (95.7\%) and specificity (52.6\%) rates. After exclusion from the analysis of illiterate participants' data, the optimal cut-off point remained unchanged. The European Portuguese version of GDS-15 is an effective tool for depression screening in older adults. Further studies are needed to verify if there are factors, other than formal education, that may influence the scale's performance.
\end{abstract}

Keywords: Depression; Geriatric Depression Scale; older adults; screening.

Exploración de la capacidad de screening de la versión europea portuguesa de la Geriatric Depression Scale de 15 items

Resumen: El objetivo del estudio fue comparar la capacidad de cribado de la versión europea portuguesa de la Geriatric Depression Scale de 15 ítems (GDS-15) respecto a los criterios del DSM-5 en relación con el trastorno depresivo mayor. El estudio fue multicéntrico e incluyó 139 ancianos (23 con diagnóstico de depresión) reclutados en un contexto de atención primaria. La sensibilidad y la especificidad para diferentes puntos de corte fueron obtenidas a través de curvas ROC. La relación de sensibilidad y especificidad reveló ser mejor en el punto de corte $\geq 4.5$, resultante en sensibilidad del $95.7 \%$ y especificidad del $52.6 \%$. Después de excluirse del análisis de los datos los participantes sin educación formal, el punto de corte óptimo permaneció sin cambios. La versión europea portuguesa de la escala GDS-15 es una herramienta efectiva para el screening de la depresión en ancianos. Se necesitan más estudios para verificar si hay otros factores que puedan influir en el rendimiento de la escala.

Palabras clave: Depresión; Escala de Depresión Geriátrica; ancianos; screening.

Recived: 24 January 2018; accepted: 17 May 2018

Corresponding author: Elzbieta Bobrowicz-Campos, Health Sciences Research Unit: Nursing, Nursing School of Coimbra, Avenida Bissaya Barreto (Polo A), Apartado 7001, 3046-851 Coimbra, Portugal. Correo-e: elzbieta.campos@gmail.com

Acknowledgments: The authors would like to acknowledge Rui Maia and Replicar Socialform for their contribution to study development, as well as ACES Baixo Mondego - UCSP Soure, ACES Baixo Mondego USF Briosa, ASAVIDA - Associação de Apoio Social Ajudar a Viver, Cediara - Associação de Solidariedade Social de Ribeira de Fráguas, Centro de Bem Estar Social de Alcanena, CERCIVAR - Cooperativa de Educação e Reabilitação de Crianças Inadaptadas de Ovar and Fundação João Bento Raimundo for their collaboration in data collection.

\section{Introduction}

According to the World Health Organization (WHO, 2015), about $2-3 \%$ of older adults living in the community and about $10 \%$ of older adults living in longterm care facilities are affected by depressive disorders. Furthermore, nearly one in 10 older adults suffers from subthreshold depression. Late-life depression is considered as one of the leading causes of disability, morbidity and mortality in geriatric population (Fiske, Wetherell, \& Gatz, 2009). However, due to its atypical 
profile, it is frequently underdiagnosed and undertreated (Munk, 2007; Sözeri-Varma, 2012). There is a need for an instrument that can be easily used as part of the comprehensive medical evaluation of geriatric patients, providing a valuable support for detection of depressive disorders and for monitoring the efficacy of antidepressant treatment. The Geriatric Depression Scale (GDS) is such instrument.

The GDS is a brief and easily comprehensive selfreport measure which was designed specifically for screening late-life depression (Yesavage et al., 1983). It is a highly reliable and valid instrument that allows early detection of significant mood changes and, therefore, better management of depression-related adverse consequences (Peach, Koob, \& Kraus, 2001). The GDS is a time-saving instrument with a simple response format (yes/no), which facilitates its use in different healthcare settings (Jongenelis et al., 2005; Peach et al., 2001).

The original version of GDS (Yesavage et al., 1983) contains 30 items focused on motivation, future/past orientation, energy, fatigue and mood itself, but not on somatic complaints, as the latter may just reflect the aging processes or result from other common medical problems in later life (Fiske et al., 2009). The GDS items also focus on subjective cognitive complaints and atypical symptoms common in late-life depression, such as anxiety and irritability (Munk, 2007). Shorter versions of the GDS, composed by $1,4,5,10,12$ or 15 items, have also been developed (Jongenelis et al., 2005). They were shown to have a potential clinical value in different medical settings (Almeida \& Almeida, 1999; Jongenelis et al., 2005; Mitchell, Bird, Rizzo, \& Meader, 2010). However, it is still unknown which of these time-saving alternatives is the most reliable and valid.

The usefulness of GDS seems to be limited in some special populations. According to some authors (Debruyne et al., 2009), the validity and reliability of the scale diminish considerably in patients with Alzheimer's Disease. Schwarzbach et al. (2014) have concluded that, due to its self-report format, the GDS is less suitable for older adults with cognitive limitations, while Chiesi et al. (2018) have demonstrated that cognitively impaired individuals are more likely to answer the GDS items on memory problems and fears about the future in a biased way. Other authors (Cwikel \& Ritchie, 1989; Kim, Prince, Shin, \& Yoon, 2001) have identified a high number of GDS misclassifications in subjects with no formal education or a very low education level.

On the other hand, Debruyne et al. (2009), Jongenelis et al. (2005) and Midden and Mast (2017) have confirmed that the GDS can be reliably used in older adults with mild to moderate cognitive impairment. Other authors (Ertan, Ertan, Kızıltan, \& Uyguçgil, 2005; Huang, Hsieh, Wu, \& Lu, 2017; Weintraub, Oehlberg, Katz, \& Stern, 2006) have attested the reliability and validity of the GDS among patients with Parkinson's Disease. GDS has also been identified as a suitable tool for screening purpose in older adults with different gender, educational level and age (Conradsson, 2013; Chiesi et al., 2017; Dias et al., 2017).

The GDS has been widely used in different countries, being translated into more than 30 languages, including Portuguese. The adaptation of the 15-item version of GDS into European Portuguese started in 2010 (Apóstolo, 2011). In the sample of 195 older adults (mean age: 73 years; $63 \%$ with education level $\leq 4$ years), the GDS-15 revealed a Cronbach's alpha value of .83 . For the concurrent validation, the depression subscale of the Depression Anxiety and Stress Scale-21 (DASS-21; Lovibond \& Lovibond, 1995) was used, showing a strong association $(=.70)$ with GDS-15.

Later, the European Portuguese version of GDS15 was administered to 889 older adults (mean age: 78 years; $89 \%$ with education level $\leq 4$ years). In this sample, Cronbach's alpha value was .83 (Apóstolo et al., 2014). The psychometric properties of the European Portuguese versions of GDS with 5 (GDS-5) and with 10 (GDS-10) items were also assessed (Apóstolo et al., 2014). The Cronbach's alpha values were of .841 for GDS-10 and .794 for GDS-5. Both GDS-10 and GDS-5 proved to be strongly and significantly correlated with GDS-15.

There is still a need to determine the sensitivity and specificity of the European Portuguese versions of GDS against existing reference tests and calculate an adequate cut-off point for depression screening. These cut-off points have been already identified for versions of GDS15 validated for other cultural and social contexts. The authors of the Brazilian-Portuguese version of scale (Almeida \& Almeida, 1999) have determined that an optimal cut-off point for depression screening is $4 / 5$. Other authors (Herman et al., 1996; Marc, Raue, \& Bruce, 2008; Rinaldi et al., 2003) have examined the screening capacity of the Canadian, North-American and Italian versions of GDS-15, suggesting a cut-off point of $5 / 6$. It is possible that the different cut-offs proposed for these versions of GDS-15 result from the influence of sociodemographic and cultural variables; they may also reflect the differences on clinical and cognitive profile of studied samples. Nonetheless, the responsible use of GDS-15 in the Portuguese healthcare system requires determination of sensitivity and specificity values for the culturally adapted and validated version of the scale, 
and selection of the most suitable cut-off point for use in routine clinical practice.

This study aimed to verify whether the European Portuguese version of GDS-15 is an efficient method for depression screening in community-dwelling adults aged 65 years and over, using as a gold standard diagnostic criteria for major depressive episode, derived from the Diagnostic and Statistical Manual of Mental Disorders, 5th edition (DSM-5) (American Psychiatric Association [APA], 2013). Data on the 5- and 10-item GDS have been presented elsewhere (Apóstolo, Bobrowicz-Campos, Reis, Henriques, \& Correia, 2018).

\section{Method}

\section{Participants}

The Local Ethics Committee of the Health Sciences Research Unit: Nursing (UICISA: E) approved the study (Opinion 11-11/2010), and all participants gave their informed consent.

The initial study sample consisted of 144 older adults aged $\geq 65$ years, recruited in general practitioner consultations, adult day care centers and nursing homes in several urban, rural and transitory areas in the Central Region of Portugal. To ensure accuracy of data obtained, all participants were screened for cognitive impairment with the 6-Item Cognitive Impairment Test (6CIT; Brooke \& Bullock, 1999). The Portuguese version of this test (Apóstolo, Paiva, da Silva, Santos, \& Schultz, 2017; Paiva \& Apóstolo, 2015) was shown to have a high test-retest reliability $(r=.95)$ and good internal consistency $(\alpha=.88)$. For the purpose of this study, the 6 CIT cut-off $\leq 21$ was used, indicating that at least some of the cognitive skills such as orientation in time and space, or working memory and attention, or long-term memory remain preserved. The final study sample was composed of 139 older adults, 84 females and 55 males. The socio-demographic characteristics of the sample are presented in Table 1.

\section{Instruments and procedure}

The study was conducted from January 2016 to February 2017. All participants completed the European Portuguese version of GDS-15 (Apóstolo et al., 2014) and were screened for the presence of major depressive episode by clinical interview using DSM5 criteria (APA, 2013). Data was collected during two separate sessions conducted on the same day. The first session was carried out by the nursing team. In this session, the participants provided information on their
Table 1. Demographic, clinical and neuropsychological characteristics of study participants

\begin{tabular}{ll}
\hline Gender (number): Male/Female & $55 / 84$ \\
Age (years): Mean \pm SD (Range) & $77.68 \pm 7.11(65-96)$ \\
$\begin{array}{l}\text { Education (years): Mean } \pm \text { SD (Range) } \\
\text { Marital Status (\%): single/married/ }\end{array}$ & $2.59 \pm 4.79(0-21)$ \\
$\begin{array}{l}\text { widowed/divorced } \\
\text { 6CIT (score): Mean } \pm \mathrm{SD} \text { (Range) }\end{array}$ & $6.88 \pm 5.98(0-21)$ \\
6CIT score (\%): $<10 / \geq 10$ & $64.7 / 35.3$ \\
$\begin{array}{l}\text { GDS (score): Mean } \pm \mathrm{SD} \text { (Range) } \\
\text { DSM-5 Criteria (number): Mean } \pm \mathrm{SD}\end{array}$ & $5.42 \pm 4.06(0-15)$ \\
(Range)
\end{tabular}

Note. 6CIT: Six-item Cognitive Impairment Test; DSM-5: Diagnostic and Statistical Manual of Mental Disorders, 5th edition; GDS: Geriatric Depression Scale.

sociodemographic features, and then answered the hetero-applied questions of GDS-15. Each "yes" answer was rated with 1 point, and each "no" answer with 0 points, except for items 1, 5, 7, 11 and 13 which were reversely coded. A high GDS score suggests the presence of depressive symptoms of clinical significance, while a low score indicates the absence of clinically relevant symptoms.

The second session was conducted by appropriately trained medical team (general practitioner and clinical psychologist) unaware of the GDS-15 score obtained by participants. During this session, the semi-structured diagnostic interview assessing DSM-5 criteria was administered. The subjects were classified as having major depressive episode when (i) they met at least five of the DSM-5 symptoms during the same two-week period, with one of the symptoms being depressed mood or loss of interest or pleasure; (ii) their functioning was significantly changed from the previous level; and (iii) the present symptoms were not attributable to the physiological effects of a substance or to another medical condition, and were not better explained by any other affective or psychotic disorder. The severity of this episode was evaluated according to the severity of present symptoms and their impact on different areas of functioning.

\section{Statistical analysis}

The internal consistency of GDS-15 was measured using Cronbach's alpha coefficient. The receiver operating characteristic (ROC) curve was plotted for GDS-15 score and DSM-5 diagnosis (present/absent) to 
compare the sensitivity and specificity of each threshold for major depressive episode. The optimal cut-off point on the ROC curve was calculated using the maximal value of the Youden index, that is, the maximal value of "Sensitivity + Specificity - 1" (Fluss, Faraggi, \& Reiser, 2005). Other standard summary measures of test accuracy, such as positive and negative predictive values, and positive and negative likelihood ratios were also calculated.

The Wilcoxon - Mann-Whitney test for two independent samples was used to analyze the distribution of GDS-15 and 6CIT scores in participants with and without depression according to DSM-5 criteria. The effect size was calculated using a formula $r=Z / \sqrt{ } N$ (Field, 2004). The obtained values were interpreted based on indications proposed by Cohen (1988), with $r$ $\geq .20$ and $<.50$ being considered as indicative of small effect size, $r \geq .50$ and $<.80$ of moderate effect size and $r \geq .80$ of large effect size.

An analysis of the distribution of the GDS-15 score in participants without depression and with different degrees of symptom severity was based on a KruskalWallis test for independent samples. Differences between groups were analyzed using the pairwise multiple comparisons of mean ranks. To determine the effect size, the Partial Eta Squared test $\left(\eta_{\mathrm{p}}^{2}\right)$ was used.
The interpretation of $\eta_{\mathrm{p}}^{2}$ values was based on Cohen's (1988) and Marôco's (2011) suggestions, with $\eta_{p}^{2}>.50$ indicating a very large effect size, $\eta_{\mathrm{p}}^{2}>.25$ and $\leq .50$ a large effect size, $\eta_{\mathrm{p}}^{2}>.05$ and $\leq .25$ a medium effect, and $\eta_{\mathrm{p}}^{2} \leq .05$ a small effect size.

Additionally, to analyze whether GDS-15 scores can be influenced or not by cognitive capacity, a nonparametric ANCOVA was performed using mean ranks of both the dependent variable and covariate. The probability levels of .05 were considered as significant. Data were analyzed using the SPSS Statistics (v. 24, IBM SPSS, New York) program.

\section{Results}

\section{Reliability of GDS-15}

As can be seen in Table 2, item means ranged from .05 (item 11) to .53 (item 6). With regard to item-total correlations, four were found to be strong (items 2, 12, 14 and $15 ; r \geq .70$ ), two were shown to be weak (items 11 and $13 ; r \leq .40$ ), and the remaining nine were revealed to be moderate $(.40<r<.70)$. The corrected itemtotal correlations ranged between .26 (item 13) and .75 (item 12). Internal consistency of GDS-15 estimated by Cronbach's alpha was shown to be high $(\alpha=.86)$.

Table 2. Statistics of the item and of the item with the total GDS-15

\begin{tabular}{lccccc}
\hline Item & Item mean & $\begin{array}{c}\text { Item } \\
\text { standard } \\
\text { deviation }\end{array}$ & $\begin{array}{c}\text { Item-total } \\
\text { correlation }\end{array}$ & $\begin{array}{c}\text { Corrected } \\
\text { item-total } \\
\text { correlation }\end{array}$ & $\begin{array}{c}\text { Alpha if } \\
\text { item deleted }\end{array}$ \\
\hline 1. Are you basically satisfied with your life & .20 & .41 & .51 & .43 & .86 \\
2. Have you dropped many of your activities and interests & .49 & .50 & .63 & .54 & .85 \\
3. Do you feel that your life is empty & .52 & .50 & .70 & .63 & .85 \\
4. Do you often get bored & .52 & .50 & .64 & .56 & .85 \\
5. Are you in good spirits most of the time & .18 & .39 & .47 & .39 & .86 \\
6. Are you afraid that something bad is going to happen to you & .53 & .50 & .62 & .53 & .85 \\
7. Do you feel happy most of the time & .23 & .43 & .51 & .42 & .86 \\
8. Do you often feel helpless & .38 & .49 & .63 & .55 & .85 \\
9. Do you prefer to stay at home. rather than going out and & .39 & .49 & .43 & .33 & .86 \\
doing new things & & & & .45 & .86 \\
10. Do you feel you have more problems with memory & .34 & .48 & .54 & .45 & .86 \\
than most & & & & .37 & .84 \\
11. Do you think it is wonderful to be alive now & .05 & .22 & .37 & .32 & .87 \\
12. Do you feel pretty worthless the way you are now & .45 & .50 & .80 & .75 & .26 \\
13. Do you feel full of energy & .31 & .46 & .36 & .69 & .84 \\
14. Do you feel that your situation is hopeless & .37 & .49 & .75 & .73 & .66 \\
15. Do you think that most people are better off than you are & .50 & .50 & & & .85 \\
\hline
\end{tabular}


GDS-15 score in older adults with and without depression

Of 139 older adults included in the study, 23 met the DSM-5 diagnostic criteria for major depressive episode and 116 did not. Thirteen depressed participants and 22 non-depressed participants were medicated with antidepressants. Nine depressed and 81 non-depressed participants were not given antidepressants. In the remaining cases, no data were provided. The means of GDS-15 score in the groups of depressed and nondepressed older adults were $8.91( \pm 3.30$, range 3-15) and 4.73 ( \pm 3.84 , range $0-13)$, respectively. The differences were statistically significant $(p<.001, r=.36)$.

Participants were further classified by symptom severity. The criteria for mild depressive episode were met in three subjects, for moderate depressive episode in four subjects, and for severe depressive episode in six subjects. In 10 cases, data on symptom severity was missing. The GDS-15 mean score was $7.33( \pm 2.08$, range 5-9) in mildly depressed patients, $9.75( \pm 2.22$, range 7-12) in moderately depressed patients, and 12.67 ( \pm 1.21 , range 12-15) in severely depressed patients. The graphical representation of the GDS score distribution in participants with and without depression can be found on Figure 1 .

Figure 1. The 15-item Geriatric Depression Scale score for participants with mild, moderate, severe and no depression according to DSM-5 criteria $(n=129)$.

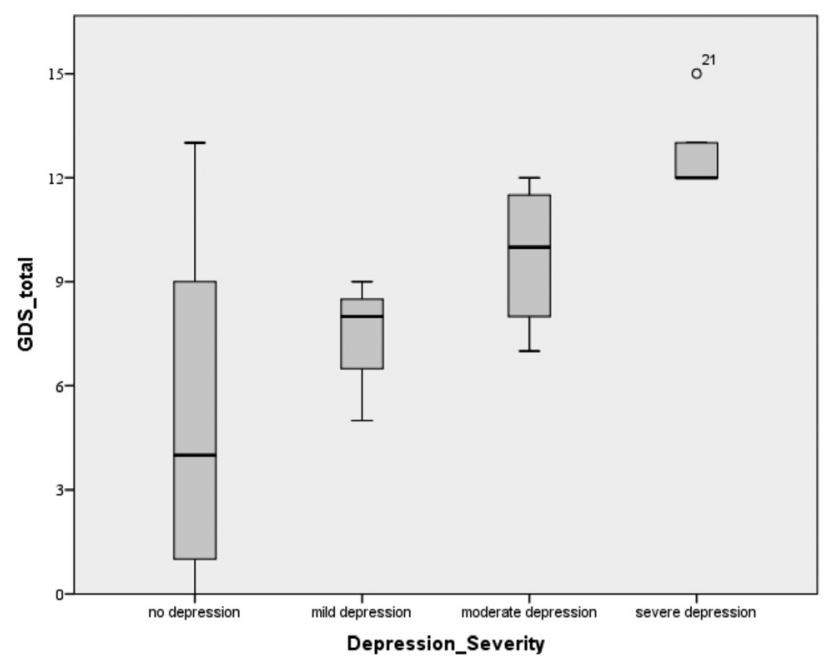

Note. Horizontal Axis: Severity of depressive symptoms according to DSM-5 criteria; Vertical Axis: The 15-item Geriatric Depression Scale score. Dark lines indicate mean scores. Boxes represent $95 \%$ confidence intervals of the mean.

The distribution of the GDS-15 score in groups of non-depressed older adults and older adults with different degrees of severity of depressive symptoms was significantly different $(p<0.001)$. The pairwise multiple comparisons of mean ranks have evidenced that the GDS score obtained by non-depressed participants differed significantly from that obtained by patients with moderate $(p=.020)$ or severe $(p<.001)$ depression, but not with mild depression $(p=.307)$. The effect size was .176. Patients with different degrees of severity of depressive symptoms did not differ significantly on the GDS score (patients with mild and moderate depression: $p=.440$, patients with mild and severe depression: $p=.110$; patients with moderate and severe depression: $p=.403$ ).

\section{GDS-15 and 6CIT score}

The mean score on 6CIT was $9.78( \pm 5.49)$ in depressed patients and $6.30( \pm 5.92)$ in non-depressed patients. The observed differences were shown to be statistically significant ( $p=.006, r=.24)$. To analyze whether these differences on cognitive capacity could influence the GDS score, the non-parametric ANCOVA was performed. After adjusting for initial between-group differences on the 6CIT score, the differences between depressed and non-depressed participants on the GDS15 score remained significant $(p<.001)$.

\section{Sensitivity and specificity of GDS-15}

As it can be seen on the Figure 2, the ROC curve analysis of GDS-15 score and DSM-5 diagnosis (present vs absent) resulted in an AUC of $.78(95 \% \mathrm{CI}=.69-$ $.87 ; p<.001)$. The values of sensitivity and specificity for different cut-off points of GDS-15 are presented in Table 3. The cut-off point indicated by maximal Youden Index was $\geq 4.5$ resulting in a sensitivity of $95.7 \%$ and a specificity of $52.6 \%$. Positive and negative predictive values and positive and negative likelihood ratios for cut-off point $\geq 4.5$ are presented in Table 4 .

The exclusion of the data obtained by participants with no formal education $(n=17)$ from ROC curve analysis had no significant impact on AUC $(=.78 ; 95 \% \mathrm{CI}=.69$ - .88; $p<.001)$. Also in this case the optimal cut-off point for GDS- 15 was $\geq 4.5$ resulting in a sensitivity of $100 \%$ and a specificity of $53 \%$. Due to reduced number of patients classified by severity of symptoms, the ROC curves for GDS-15 score and DSM-5 criteria for mild, moderate and severe depression were not performed.

\section{Discussion}

The aim of the present study was to verify whether the European Portuguese version of GDS-15 can be 
Table 3. Sensitivity, specificity and Youden Index of the 15-item Geriatric Depression Scale

\begin{tabular}{crrc}
\hline Cut-off point & Sensitivity & Specificity & Youden Index \\
\hline$\geq 0.5$ & $100 \%$ & $17.2 \%$ & 0.17 \\
$\geq 1.5$ & $100 \%$ & $32.0 \%$ & 0.31 \\
$\geq 2.5$ & $100 \%$ & $37.9 \%$ & 0.38 \\
$\geq 3.5$ & $95.7 \%$ & $45.7 \%$ & 0.41 \\
$\geq \mathbf{4 . 5}$ & $\mathbf{9 5 . 7 \%}$ & $\mathbf{5 2 . 6 \%}$ & $\mathbf{0 . 4 8}$ \\
$\geq 5.5$ & $78.3 \%$ & $57.8 \%$ & 0.36 \\
$\geq 6.5$ & $73.9 \%$ & $63.8 \%$ & 0.38 \\
$\geq 7.5$ & $56.5 \%$ & $69.8 \%$ & 0.26 \\
$\geq 8.5$ & $52.2 \%$ & $72.4 \%$ & 0.25 \\
$\geq 9.5$ & $43.5 \%$ & $86.2 \%$ & 0.30 \\
$\geq 10.5$ & $43.5 \%$ & $96.6 \%$ & 0.40 \\
$\geq 11.5$ & $34.8 \%$ & $97.4 \%$ & 0.32 \\
$\geq 12.5$ & $8.7 \%$ & $98.3 \%$ & 0.07 \\
$\geq 14.0$ & $4.3 \%$ & $100 \%$ & 0.04 \\
\hline
\end{tabular}

Note. In bold: values of cut-off point, sensitivity and specificity for the maximal Youden Index.

efficiently used to detect major depression in communitydwelling older adults. The diagnosis of major depressive episode was based on DSM-5 criteria (APA, 2013). Data were collected in primary healthcare settings, adult day care centers and nursing homes. All participants were screened for cognitive impairment with the 6CIT. Apóstolo et al. (2017) have proposed a 6CIT score $\geq 10$ as the threshold for cognitive impairment in the Portuguese population. However, given the evidence showing that the GDS can be reliably used in older adults with cognitive impairment of mild and moderate severity (Conradsson et al., 2013; Debruyne et al., 2009; Jongenelis et al., 2005), it was decided that the subjects who did not manifest severe deterioration in multiple cognitive domains should remain in the study. Therefore, only those who obtained a score $>21$ on 6CIT were excluded. Participants with a 6 CIT score between 10 and 21 , indicating the possible presence of mild to
Figure 2. ROC curve for the 15-item Geriatric Depression Scale score, using DSM-5 criteria for depression as "gold standard".

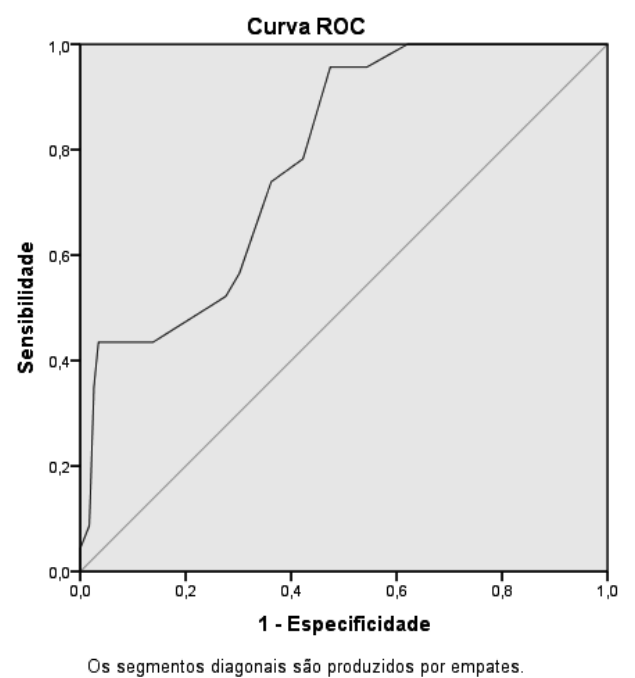

moderate cognitive decline, represented one-third of the final sample.

The internal consistency of the European Portuguese version of GDS-15 was previously reported as being high (Apóstolo et al., 2014). Our study has confirmed this finding. The comparison of GDS-15 scores in older adults with and without depression according to DSM-5 criteria revealed that the GDS- 15 has a good discriminant capacity. After considering the potential interfering effect of cognitive capacity, the differences on the GDS score between depressed and non-depressed participants remained significant, which indicates that the analyzed version of the scale is suitable for use in older adults with mild to moderate cognitive impairment. These results are consistent with those found by other authors (Debruyne et al., 2009; Jongenelis et al., 2005; Midden $\&$ Mast, 2017).

The sensitivity and specificity values of GDS-15 were calculated for different cut-off points, and cut-off point $\geq 4.5$ was shown to be the most appropriate for screening purposes. At this threshold, the sensitivity

Table 4. Screening properties of the 15 -item Geriatric Depression Scale for cut-off $\geq 4.5$

\begin{tabular}{ccccccc}
\hline Sensitivity & Specificity & AUC & PPV & NPV & LR+ & LR- \\
\hline 0.96 & 0.53 & $.78^{*}$ & 0.29 & 0.99 & 2.02 & 0.08 \\
$(0.87-1.04)$ & $(0.43-0.62)$ & $(0.692-0.87)$ & $(0.18-0.39)$ & $(0.95-1.02)$ & $(1.63-2.49)$ & $(0.01-0.57)$ \\
\hline
\end{tabular}

Note. AUC: area under the curve; LR-: negative likelihood ratio; LR+: positive likelihood ratio; NPV: negative predictive value; PPV: positive predictive value. Numbers in parentheses show a $95 \%$ confidence interval. ${ }^{*} p<0.001$. 
and specificity of GDS-15 reached values of $95.7 \%$ and $52.6 \%$, respectively. In comparison, the use of cutoff point $\geq 5.5$ resulted in a sensitivity of $78.3 \%$ and a specificity of $57.8 \%$. Thus, cut-off point $\geq 4.5$ seems to ensure more accurate detection of patients with geriatric depression; however, its ability for identifying nondepressed patients is quite reduced.

The use of cut-off between four and five points for GDS15 was also considered by other authors. Based on a metaanalysis of diagnostic data from 32 studies on brief versions of GDS, Pocklington, Gilbody, Manea and McMillan (2016) have concluded that for the 15-item version of the scale the recommended cut-off point is 5 , with a pooled sensitivity of .89 and specificity of 0.77 . One of the studies meta-analyzed by Pocklington et al. (2016) has referred a Brazilian-Portuguese version of GDS-15 (Almeida \& Almeida, 1999), examined in the sample of outpatients from mental health clinic. According to this study authors (Almeida \& Almeida, 1999), the 4/5 cut-off point produces robust results for non-case/case identification. The screening utility of 4/5 cut-off point of BrazilianPortuguese version of the GDS-15 was also confirmed by other authors (Dias et al., 2017). In this case, a targeted sample included low-educated and oldest-old individuals. Although high sensitivity levels were additionally found for cut-off points of 2, 3 and 4 , the corresponding specificity values were only shown to be satisfactory for a cut-off point of 4 (Pocklington et al., 2016).

Interestingly, the analysis of the GDS- 15 performance in a sample of oldest-old adults with good cognitive function (Craen, Heeren, \& Gussekloo, 2003) indicated that the optimal cut-off point for depression screening is $2 / 3$. In comparison, other authors (Costa et al., 2016) affirmed that in older adults without neurocognitive disorders the cut-off of 6 should be used for purposes of depression detection. The mean age of participants included in this last study was of 71 years. These divergent findings suggest that the discriminant validity of GDS-15 may depend on the participants' age, and thus further studies are needed to verify whether this variable should be considered or not in the definition of the optimal cut-off point.

The influence of the education level on the performance on the GDS-15 also requires to be studied systematically. As mentioned above, there is evidence showing (Cwikel \& Ritchie, 1989; Kim et al., 2001) that lack of formal education or a low education level can lead to misclassifications in the shortened versions of the scale. On the other hand, the use of the dichotomized format of response options seems to reduce the risk of classification errors, since it does not require the gradation of symptomatology levels. According to some authors, the yes/no or agree/disagree formats are mostly appropriate in older adults with cognitive limitations (e.g. Mababu \& Ruiz-Sánchez, 2016). However, their use in samples without cognitive impairment may lead to the loss of relevant information. The results obtained in the present study have demonstrated that the screening capacity of the European Portuguese version of GDS-15 is not affected by having or not having formal education. However, the participants without any formal education represented $12 \%$ of the study sample. Comparatively, $68.3 \%$ of the sample had education level between one and four years. Thus, it is possible that the sensitivity and specificity results obtained for the analyzed GDS version are mainly representative for older adults with lower education levels, being necessary to verify whether the proposed cut-off point $\geq 4.5$ is also adequate for persons with more years of formal education.

Furthermore, the meta-analysis by Pocklington et al. (2016) has suggested that the suitability of the cut-off point may depend on the healthcare setting. Namely, the comparison of diagnostic data obtained in different settings showed that the cut-off point of 5 is appropriate for use in older adults evaluated in the context of primary and secondary healthcare, whereas for adults in a community setting the cut-off point of 6 seems to be more appropriate.

This study had some limitations. First, the study sample is of convenience and non-probabilistic, which limits substantially the generalizability of the study findings to a wider population. To reduce the impact of this limitation, the recruitment of older adults was carried out in different geographical locations and included different settings. Second, the generalizability of the study findings may have also been affected by sample size. Although 139 older adults were included in the study, only 23 of them met DSM-5 criteria for major depressive episode. Moreover, in 10 cases the information on symptom severity was missing, and therefore, it was impossible to perform ROC curve analyses of the 15-item GDS scale for each diagnostic category (mild, moderate and severe depression). The results obtained might have also been affected by antidepressant medication intake, which was reported in relation to thirty-five participants. However, due to differences in the type and dosage of the medication taken, it was difficult to examine the effect of this variable on the participants' answers. There is a need for further research with larger samples to strengthen the generalizability of the study findings. It is also necessary to verify if the proposed cut-off point is suitable in secondary healthcare.

In conclusion, the European Portuguese version of GDS-15 is a reliable instrument for screening major 
depressive episode in older adults. This brief instrument is simple to understand and easy-to-use, and it provides relevant data on the patient's clinical status in a less tiring, time-saving and resource-saving way. It is also appropriate for use in patients with mild and moderate, but not severe cognitive decline. For all these reasons, the use of GDS15 in the primary healthcare and in the long-term care facilities seems to be justified. However, more studies are needed to confirm the screening capacity of GDS-15 and to verify if there are factors other than high levels of dementia that can influence the performance of the scale.

\section{Conflict of interests}

The authors report no conflicts of interest

\section{References}

Almeida, O. P., \& Almeida, S.A. (1999). Short versions of the Geriatric Depression Scale: A study of their validity for the diagnosis of a major depressive episode according to ICD-10 and DSM-IV. International Journal of Geriatric Psychiatry, 14, 858-865.

American Psychiatric Association. (2013). Diagnostic and statistical manual of mental disorders, fifth edition. Washington, DC, USA: American Psychiatric Association.

Apóstolo, J. (2011). Adaptation into European Portuguese of the Geriatric Depression Scale (GDS-15). Revista de Enfermagem Referência - Suplemento Actas e Comunicações XI Conferência Iberoamericana de Educação em Enfermagem, Vol. II, 3(4 Supl.), 452.

Apóstolo, J., Bobrowicz-Campos, E., Reis, I., Henriques, S., \& Correia, C., (2018). Screening capacity of Geriatric Depression Scale with 10 and 5 items. Revista de Enfermagem Referência, IV(16), 29-38.

Apóstolo, J., Loureiro, L., Reis, I., Silva, I., Cardoso, D., \& Sfetcu, R. (2014). Contribution to the adaptation of the Geriatric Depression Scale -15 into Portuguese. Revista de Enfermagem Referência, IV(3), 65-73.

Apóstolo, J., Paiva, D., da Silva, R., Santos, E., \& Schultz, T. (2017). Adaptation and validation into Portuguese language of the Six Item Cognitive Impairment Test (6CIT). Aging \& Mental Health, 0(0), 1-6.

Brooke, P., \& Bullock, R. (1999). Validation of a 6-item cognitive impairment test with a view to primary care usage. International Journal of Geriatric Psychiatry, 14(11), 936-940.

Chiesi, F., Primi, C., Pigliautile, M., Baroni, M., Ercolani, S., Boccardi, V., ... Mecocci, P. (2017). Is the 15-item Geriatric Depression Scale a fair screening tool? A differential item functioning analysis across gender and age. Psychological Reports, $0(0), 1-16$.

Chiesi, F., Primi, C., Pigliautile, M., Baroni, M., Ercolani, S., Paolacci, L., ... Mecocci, P. (2018). Does the 15-item Geriatric Depression Scale function differently in old people with different levels of cognitive functioning? Journal of Affective Disorders, 227, 471-476.
Cohen, J. (1988). Statistical power analysis for the behavioral sciences ( $2^{\mathrm{a}}$ ed.). New York, USA: Erlbaum, Hillsdale.

Conradsson, M., Rosendahl, E., Littbrand, H., Gustafson, Y., Olofsson, B., \& Lövheim, H. (2013). Usefulness of the Geriatric Depression Scale 15-item version among very old people with and without cognitive impairment. Aging \& Mental Health, 17(5), 638-645.

Costa, M., Diniz, M., Nascimento, K., Pereira, K., Dias, N., Malloy-Diniz, L., \& Diniz, S. (2016). Accuracy of three depression screening scales to diagnose major depressive episodes in older adults without neurocognitive disorders. Revista Brasileira de Psiquiatria, 38, 154-156.

Craen, A., Heeren, T. J., \& Gussekloo, J. (2003). Accuracy of the 15 -item Geriatric Depression Scale (GDS-15) in a community sample of the oldest old. International Journal of Geriatric Psychiatry, 18, 63-66.

Cwikel, J., \& Ritchie, K. (1989). Screening for depression among the elderly in Israel: an assessment of the Short Geriatric Depression Scale (S-GDS). The Israel Medicine Association Journal, 25(3), 131-137.

Debruyne, H., Van Buggenhout, M., Le Bastard, N., Aries, M., Audenaert, K., De Deyn, P. P., \& Engelborghs, S. (2009). Is the geriatric depression scale a reliable screening tool for depressive symptoms in elderly patients with cognitive impairment? International Journal of Geriatric Psychiatry, 24(6), 556-562.

Dias, F., Teixeira, A., Guimarães, H., Barbosa, M., Resende, E., Beato, R., Carmona, K., \& Caramelli, P. (2017). Accuracy of the 15-item Geriatric Depression Scale (GDS-15) in a community-dwelling oldest-old sample: the Pietà Study. Trends in Psychiatry and Psychotherapy, 39(4), 276-279.

Ertan, F. S., Ertan, T., Kızıltan, G., \& Uyguçgil, H. (2005). Reliability and validity of the Geriatric Depression Scale in depression in Parkinson's disease. Short report. Journal of Neurology, Neurosurgery \& Psychiatry, 76, 1445-1447.

Field, A. (2004). Discovering statistics using SPSS for Windows. New York, USA: Sage Publication.

Fiske, A., Wetherell, J. L., \& Gatz, M. (2009). Depression in older adults. Annual Review of Clinical Psychology, 5, 363-389.

Fluss, R., Faraggi, D., \& Reiser, B. (2005). Estimation of the Youden Index and its associated cutoff point. Biometrical Journal, 47(4), 458-472.

Herrmann, N., Mittmann, N., Silver, I. L., Shulman, K. I., Busto, U. A., Shear, N. H., \& Naranjo, C. A. (1996). A validation study of the Geriatric Depression Scale short form. Research Article. International Journal of Geriatric Psychiatry, 11(5), 457-460.

Huang, S., Hsieh, C., Wu, R., \& Lu, W. (2017). Test-retest reliability and minimal detectable change of the Beck Depression Inventory and the Taiwan Geriatric Depression Scale in patients with Parkinson's disease. Plos One, 12(9), 1-19.

Jongenelis, K., Pot, A. M., Eisses, A. M., Gerritsen, D. L., Derksen, M., Beekman, A. T., ... \& Ribbe, M. W. (2005). Diagnostic accuracy of the original 30-item and shortened versions of the Geriatric Depression Scale in nursing home patients. International Journal of Geriatric Psychiatry, 20(11), 1067-1074.

Kim, J. M., Prince, M. J., Shin, I. S., \& Yoon, J. S. (2001). Validity of Korean Form of Geriatric Depression Scale (KGDS) among 
cognitively impaired Korean elderly and the development of a 15-item short version (KGDS-15). International Journal of Methods in Psychiatric Research, 10, 204-210.

Lovibond, S. H., \& Lovibond, P. F. (1995). Manual for the Depression Anxiety Stress Scales ( ${ }^{\text {nd }}$ ed). Sydney, Australia: Psychology Foundation.

Mababu, R., \& Ruiz-Sánchez, G. (2016). Factorial validity of the Spanish version of the Geriatric Anxiety Inventory (GAI): Empirical analysis of its structure and dimensions. Revista de Psicopatología y Psicología Clínica, 21(3), 201-208.

Marc, L. G., Raue, P. J., \& Bruce, M. L. (2008). Screening performance of the 15 -item geriatric depression scale in a diverse elderly home care population. The American Journal of Geriatric Psychiatry, 16(11), 914-921.

Marôco, J. (2011). Análise Estatística com o SPSS Statistics [Statistical Analysis with SPSS Statistics] (5th ed.). Pêro Pinheiro, Portugal: Report Number - Análise e Gestão de Informação, Lda.

Midden, A., \& Mast, B. (2017). Differential item functioning analysis of items on the Geriatric Depression Scale-15 based on the presence or absence of cognitive impairment. Aging \& Mental Health, 14 (2), 1-7.

Mitchell, A.J., Bird, V., Rizzo, M., \& Meader, N. (2010). Which Version of the Geriatric Depression Scale is most useful in medical settings and nursing homes? Diagnostic validity meta-analysis. The American Journal of Geriatric Psychiatry, 18(12), 1066-1077.

Munk, K. (2007). Late-life depression: Also a field for psychotherapists! Part one. Nordic Psychology, 59(1), 7-26.

Paiva, D., \& Apóstolo, J. (2015). Estudo de adaptação transcultural e validação do six item cognitive impairment test. In J. Apóstolo, \& M. Almeida (eds.), Elderly Health Care Nursing (pp. 3-18). Coimbra, Portugal: Unidade de Investigação em Ciências da Saúde: Enfermagem, Escola Superior de Enfermagem de Coimbra.

Peach, J., Koob, J. J., \& Kraus, M. J. (2001). Psychometric evaluation of the Geriatric Depression Scale (GDS): Supporting its use in health care settings. Clinical Gerontology, 23(3/4), 57-68.

Pocklington, C., Gilbody, S., Manea, L., \& McMillan, D. (2016). The diagnostic accuracy of brief versions of the Geriatric Depression Scale: A systematic review and meta-analysis. International Journal of Geriatric Psychiatry, 31, 837-857.

Rinaldi, P., Mecocci, P., Benedetti, C., Ercolani, S., Bregnocchi, M., Menculini, G., ... \& Cherubini, A. (2003). Validation of the five-item geriatric depression scale in elderly subjects in three different settings. Journal of American Geriatrics Society, 51(5), 694-698.

Schwarzbach, M., Luppa, M., Hansen, H., König, H. H., Gensichen, J., Petersen, J. J., ... \& MultiCare study group (2014). A comparison of GP and GDS diagnosis of depression in late life among multimorbid patients - results of the MultiCare study. Journal of Affective Disorders, 168, 276-283.

Sözeri-Varma, G. (2012). Depression in the elderly: Clinical features and risk factors. Aging and Disease, 3(6), 465-471.

Weintraub, D., Oehlberg, K. A., Katz, I. R., \& Stern, M. B. (2006). Test characteristics of the 15-item Geriatric Depression Scale and Hamilton Depression Rating Scale in Parkinson disease. American Journal of Geriatric Psychiatry, 14(2), 169-175.

World Health Organization. (2015). World report on ageing and health. Geneva, Swiss: Author.

Yesavage, J. A., Brink, T. L., Rose, T. L., Lum, O., Huang, V., Adey, M., \& Leirer, V. O. (1983). Development and validation of a geriatric depression screening scale: A preliminary report. Journal of Psychiatric Research, 17(1), 37-49. 
